\title{
Trilhas teatrais no IFMA campus Codó: uma análise sobre os saberes e fazeres do corpo
}

O objetivo desta pesquisa é compreender de que modo o fazer teatral, na escola, pode mobilizar a percepção de si para além do corpo cotidiano. São analisadas 4 experiências teatrais, nominadas por trilhas, conduzidas com alunos do IFMA Codó, entre 02/2017 a 04/2018. Dentre os referenciais, LAROSSA (2014) foi fundamental para assumirmos a escrita como língua da experiência; PUPO (2006), para a percepção da amplitude da Pedagogia do Teatro enquanto campo interdisciplinar; e BOAL (2009), para compreendermos o teatro como lugar de potência no exercício do pensamento sensível, resgatando potencialidades estéticas do corpo - o qual, lamentavelmente, ainda é visto sob uma visão dualista e instrumental, bastante evidente no contexto do Ensino Técnico. A aplicação foi norteada pela pesquisaação, um caminho de investigação favorável, por acolher a não- neutralidade das pesquisadoras, as imprevisibilidades e subjetividades próprias dos processos criativos. Para coleta de dados, além da observação, foram considerados conversas de campo, registros escritos, além de fotos e vídeos. Dentre as considerações, destacamos a diversidade de caminhos possíveis para se propiciar o fazer teatral na escola, que as oportunidades de ensinar/aprender não se apresentam prontas, precisam ser construídas; e que nesta caminhada, para abrir trilhas foi preciso, por vezes, lidar com mata fechada, solicitando um estado de prontidão, disponibilidade e sensibilidade como aprendizes e professoras de teatro. No tocante aos saberes e fazeres do corpo em cena, verificamos que muitos alunos se propuseram à ação e reflexão, e que nos trajetos, novos olhares, de qualidade estética, foram lançados ao próprio corpo.

Palavras-chave: Fazer teatral. Ensino Médio/Técnico. Pedagogia do Teatro. Saberes e fazeres do corpo. Pensamento Sensível.

The purpose of this research is to understand how the theatrical doing, in school, can mobilize the perception of oneself beyond the everyday body Four theatrical experiences, nominated by trails, are students of the IFMA Codó, between 02/2017 to 04/2018. Among the references, LAROSSA (2014) was fundamental for assuming writing as a language of experience; PUPO (2006), for the perception of the amplitude of Theater Pedagogy as an interdisciplinary field; and BOAL (2009), to understand theater as a place of power in the exercise of sensible thinking, rescuing the aesthetic potentialities of the body - which, unfortunately, is still seen under a dualistic and instrumental vision, quite evident in the context of Technical Education. 
The application was guided by action research, a path of favorable research, for accepting the non-neutrality of the researcher, the unpredictability and subjectivity of the creative processes. For data collection, besides the observation, were considered field conversations, written records, as well as photos and videos. Among the considerations, we highlight the diversity of possible ways to promote theatrical performance in school, that the opportunities to teach / learn are not ready, they need to be built; and that in this walk, to open tracks it was necessary sometimes to deal with a closed forest, requesting a state of readiness, availability and sensitivity as an apprentice and theater teacher. With regard to the knowledge and actions of the body on the scene, we find that many students have set themselves up for action and reflection, and that in the paths, new looks of aesthetic quality were thrown into the body itself.

Keywords: Make theatrical. High School / Technical. Theater Pedagogy. Knowing and doing the body. Sensitive Thinking.

\section{DESBRAVANDO TRILHAS TEATRAIS}

Como transformar as aulas de Arte $^{1}$ num espaço para trabalhar os saberes do corpo? Durante a formação básica conhecemos na teoria algumas propostas, aventuramos a experimentar algumas, mas tudo muda quando adentramos a sala de aula. O repertório que levamos pode colidir com os interesses da instituição e dos próprios alunos. Diante de tantos entraves, o quê e como fazer? Estas são as motivações da presente pesquisa, desenvolvida com estudantes do IFMA, campus Codó, de 02/2017 a 04/2018, no âmbito do Mestrado Profissional em Artes PROFARTES.

A compreensão sobre a amplitude da Pedagogia do Teatro, enquanto campo interdisciplinar onde interagem saberes artísticos, estéticos, pedagógicos e culturais, foi basilar no percurso da pesquisa. Como destaca PUPO (2006, p. 109), vários fatores entram na reflexão, já que “[...] quando falamos em pedagogia teatral estamos nos referindo a uma reflexão sobre as finalidades, as condições, os métodos e os procedimentos relativos a processos de ensino/aprendizagem em teatro". Nosso foco de análise é o como, as metodologias, mas, obviamente, que elas perpassam por outros aspectos. A largueza deste campo se fez refletir na diversidade de caminhos possíveis. Em contato com centenas de alunos dos cursos médio/técnicos em Agroindústria, Agropecuária, Comércio e Informática, percebemos que

\footnotetext{
${ }^{1}$ Como não há o componente curricular Teatro nos projetos dos cursos médio/técnicos, trabalhamos os conteúdos da área dentro da disciplina Arte.
} 
não haveria um modo apenas, mas que cada grupo necessitava de um caminho próprio, exigindo procedimentos distintos.

Com base na pesquisa-ação, que pressupõe a escuta do campo e dos sujeitos, foram percorridos 4 caminhos, chamados por trilhas: a- formação de grupo teatral; b- visita de estudo em teatro de sombras humanas; c- exercício performático; d- aplicação de ementa experimental. Envolvendo diferentes grupos de alunos, as trilhas foram motivadas pela indagação: como conduzir processos teatrais que ampliem a percepção de corpo considerando as reais condições de trabalho? Depois de percorrê-las, ou melhor, de construí-las, analisamos quais qualidades corporais extra-cotidianas - comuns ao universo teatral - foram possíveis trabalhar e o alcance disto para a corporeidade. Na coleta dos dados, fizemos registros orais, escritos, fotos e vídeos.

O corpo, primeira casa, território de sentidos e subjetividades, é por vezes esquecido na escola. Por isso, tentamos possibilitar que o estudante se percebesse enquanto corpo para além da visão instrumental, experimentando sua dimensão poética e expressiva, por meio de situações em que o pensamento sensível fosse protagonista. Falamos de um pensamento não intelectualizado, vivido na carne, que pode conduzir a uma ampliação do conhecimento de si (BOAL, 2009).

$\mathrm{Na}$ análise, assumo a escrita como exercício reflexivo, como língua da experiência. Sem um sentido acabado, numa tentativa de "[...] elaborar (com outros) o sentido ou a ausência de sentido do que nos acontece" (LAROSSA, 2014, p. 68). Durante a vagarosa caminhada, ao escutar e refletir sobre as diversas vozes, compreendemos que a diversidade de caminhos de ensinar/aprender teatro é fato e ocorre por vários motivos. Dentre eles, destacamos o caminho de formação do professor. Onde está nosso alicerce? Adiantamos que muitos "outros" que estiveram conosco outrora, nos acompanharam nas trilhas. Mestres corajosos, ousados, que não se acovardavam diante dos obstáculos, serviram de inspiração. Relatos como deste aluno ${ }^{2}$ do curso técnico em Agropecuária, “[...] é muito interessante como o corpo pode criar objetos, gestos e uma infinidade de formas. O corpo (quando queremos) pode ir muito além do que pensamos", nos dizem que o cotidiano escolar, por mais conservador, sempre é potencialmente viável; mas que precisamos nos alimentar de sensibilidade e disponibilidade, para perceber as oportunidades de empreender ricas situações de aprendizagem em teatro. $\mathrm{O}$ olhar atento e estranhado da estética brechtiana serviu de impulso, para nos reinventarmos no

\footnotetext{
${ }^{2}$ A identidade do aluno foi preservada até que se finalize o trâmite documental necessário para tal publicização.
} 
lugar de professoras, fugir de fórmulas engessadas e tentar construir estratégias singulares que pudessem marcar de sentido a trajetória dos sujeitos partícipes.

BOAL, Augusto. A Estética do Oprimido. Rio de Janeiro: Garamond, 2009.

LARROSA, Jorge. Tremores: escritos sobre a experiência. 1. Ed. Belo Horizonte: Autêntica Editora, 2014;

PUPO, Maria Lúcia. Sinais de teatro-escola. Humanidades, Edição Especial Teatro PósDramático, Editora UNB, No 52, Nov. 2006, pp 109-115. 